Www.jmscr.igmpublication.org

Index Copernicus Value: 79.54

ISSN (e)-2347-176x ISSN (p) 2455-0450

crossref DOI: https://dx.doi.org/10.18535/jmscr/v7i6.147

Journal Of Medical Science And Clinical Research

IGM Publication

An Official Publication of IGM Publication

\title{
A Brainstem Auditory Evoked Potential Study to find out Auditory Pathway Status among Children with Speech \& Language Impairment
}

\author{
Authors
}

\section{Dr Sonali Majumdar ${ }^{1}$, Dr Hiya Bhattacharya ${ }^{2 *}$, Prof (Dr) Malay Dasgupta ${ }^{3}$}

${ }^{1}$ Associate Professor, Department of Physiology, R. G. Kar Medical College, Kolkata, West Bengal, India

${ }^{2}$ Demonstrator, Department of Physiology, Diamond Harbour Govt. Medical College, South 24 pargana,

West Bengal, India

${ }^{3}$ Professor, Department of Paediatric Medicine, R. G. Kar Medical College, Kolkata, West Bengal, India

*Corresponding Author

Dr Hiya Bhattacharya

Residential address- 52B, Shambhunath Pandit Street, Flat no- 303, beside Bangur Institute of

Neurosciences, Kolkata-700025, West Bengal, India

\begin{abstract}
Background: Speech and Language impairment in children have multifactorial aetiology. Among them, hearing problem plays an important role. Brainstem Evoked Response Audiometry (BERA), which can assess Brainstem Auditory Evoked Potential (BAEP), is an useful and objective screening tool toevaluate functional integrity of auditory pathway.

Aims: The study was done to observe changes of BAEP parameters in children with delayed speech and to assess auditory pathway involvement based on BERA findings.

Methods: This cross sectional study, done in Eastern region of India, included Two fifty children $(n=250)$ with delayed speech and one twenty normal children. The cases were divided into four groups according to age -Group 1(<1yr); Group 2(1-3yrs); Group3 (3-6yrs); Group 4(6-12yrs). BAEP values of each group was compared with corresponding control group of similar age and intra group comparison was also performed. Statistical analysis was done by Student t test, ANOVA and Tukey HSD post-hoc test.

Results: BAEP findings of groups were

Group 1- statistically significant prolongation of wave I in right ear

Group 2-statistically significant prolongation of Waves I, V and I-V inter peak latency in both the ears.

Group 3-statistically significant prolongation of all the Waves and I-V inter peak latency in left side and significant delay of all waves except wave I in right side.

Group 4- statistically significant prolongation of I, V Waves and I-V inter peak latency in left side and statistically significant delay of wave I in right side.

In intra group comparison.

statistically significantly prolongations were seen in

- right sided wave I latencyin group 2 than group 3

- $\quad$ right sided wave V and I-V inter wave latencies in group 1,2,3 than Group 4.

Out of 250 children, 157 children showed absent waves either in one or both the ears.

Conclusions: This study identified significant dysfunction of auditory pathway in children with delayed speech. Thereby it indicates the necessity of BERA as screening method.

Keywords: Children, Delayed speech, Auditory pathway, BERA.
\end{abstract}




\section{Introduction}

Language plays very important part in developing human intelligence and human culture. Children with speech and language impairment constitute a large group of patients attending the paediatric or otorhinolaryngology clinic. Though the exact prevalence and incidence of developmental speech and language delay is not known; various studies have reported that approximately $15-50 \%$ of children attending Paediatric Neurology clinics have developmental speech and language delay/impairment/abnormality ${ }^{[1,2]}$.

An infant begins to communicate with his/her surrounding environment from the first month of life. Though, true words generally appear around the age of 12-15 months, maintaining a rather predictable sequence. Delay or failure of normal language development is not at all a rare situation in childhood and may be due to a variety of reasons, mental handicap, autism and severe environmental deprivation, inborn disease of metabolism etc. Among these, hearing undoubtedly plays a major role in the language acquisition process $^{[1]}$.

As hearing loss is one of the major causes of impaired speech and language, numerous techniques have been tried to find out reliable and efficient screening method for determining auditory functions. Brainstem Evoked Response Audiometry (BERA), which can assess Brainstem Auditory Evoked Potential (BAEP), is a sensitive electrophysiological technique. It is an objective test, so it is reliable for children. It accurately determines the functional integrity of the auditory pathway $^{[2]}$.

This cross-sectional study evaluated, BAEP among children with delayed speech of different age group in comparison with normal children of corresponding age group. The study aimed to document whether there were BAEP changes in children with speech and language impairment; as alteration of BAEP parameters reflect auditory pathway status. This may indicate, pathology in auditory pathway, for which, diagnosis should be initiated as early as possible, preferably from birth till 3- 4 years of age ${ }^{[3]}$ because earliest initiation of treatment and rehabilitative measures are very crucial for improving linguistic development and prognosis of children.

\section{Material and Methods}

BAEP data of Two hundred and fifty $(n=250)$ children with speech and language impairment were compared with BAEP data of normal children, taken as control group. These speech impaired children were divided into four groups according to age. They were compared with corresponding control population which consists with 30 normal children of similar age in each group (i.e. 120 normal children). Intra group comparison was also done. These groups were, Group 1- consists of children aged $<1 \mathrm{yr}$ or infants, Group 2- consists of children aged 1-3yrs. or toddlers, Group 3- children aged 3-6 yrs. or preschool children, Group 4- children aged 612 yrs. or school children.

Children, suffering from impaired speech and language, were referred from Otorhinolaryngology (ENT) and Paediatrics Out Patient Department (OPD), for BERA in Applied Physiology Lab at Department of Physiology at R.G. Kar Medical College. Control group was selected from Well Baby Clinic of Paediatrics OPD, R.G. Kar Medical College. The study was conducted for five months from January 2019 to May 2019, in Department of Physiology in collaboration with Department of Paediatric Medicine \& Dept. of Otorhinolaryngology of R.G. Kar Medical College. The study was approved by the Institutional Ethics Committee, R.G. Kar Medical College, Kolkata. Severely ill or uncooperative children, children with visible congenital anomaly, chromosomal or endocrinal disorders, were excluded. Informed written consent was taken from the parents or guardians of all infants before the test.

\section{Procedure}

Brainstem Auditory Evoked Potential (BAEP) was recorded with the help of the machineNeuro- 
MEP4, Ivanovo, Russia. At first, guardians were interviewed as per the study protocol and to gather a clinical history. External ear examination was done and findings were documented. Parents or guardians of the children were explained about the test and asked to apply shampoo at the day before examination. They were told to come on test day along with children. Proper consent form was being explained and signed. They were also instructed to wake the children up in early morning of that very day, so that children remained asleep during the whole recording time as in order to exclude biologically derived noise due to muscle activity. Calm and quiet awake children were also accepted. Test was done in quiet and cool surrounding. Nuprep cleaning gel was used to clean scalp and forehead for electrode placement.

The surface electrodes were attached for recording Brainstem Auditory Evoked Potential. Electrolyte paste was used to fix the silver cup electrodes over scalp. The electrode impedance was checked and it was less than $5 \mathrm{kohm}$. The reference electrode was placed at, vertex $(\mathrm{Cz})$ and active electrodes, at both mastoids as per International 10-20 system. The mastoids, ipsilateral and contralateral to the stimulated ear are labelled $\mathrm{Mi}$ and $\mathrm{Mc}$ respectively. Over forehead, the ground electrode (Fz) was placed ${ }^{[2]}$.

Mono phasic square pulse acoustic clicks were used at 29.9 pulse/sec with click duration of 0.1 ms. Rarefaction clicks were used with $1 \mathrm{~ms} / \mathrm{Div}$. sweep speed and 0.5 micro-volt sensitivity. To find out auditory pathway status, BAEP recording was done by applying $70 \mathrm{~dB}$ stimulus intensity in ipsilateral ear and $40 \mathrm{~dB}$ lower than stimulus intensity was used as masking noise in contralateral ear. Filter setting was kept between $100 \mathrm{~Hz}-3000 \mathrm{~Hz}$. Two thousand responses were averaged and two such recordings were taken to assess reproducibility.

The absolute latencies of waves I,III, V and the I$\mathrm{V}$ inter peak latency of brainstem auditory evoked potential at $70 \mathrm{~dB}$ were compared between the study group and control group to assess any significant difference of wave latencies. When BAEP parameters of cases were prolonged in respect to these normal range of values of control population, or when BAEP waves are absent, both considered as abnormal.

\section{Statistical analysis}

At $70 \mathrm{~dB}$ intensity BAEP changes of 250 children of four study groups were compared with total120 normal children of corresponding control group. To compare data of these groups with control population, Student's t-test was applied and statistical analysis was done with Graph Pad Quick Calc software, California, USA. For intra group comparison, one way ANOVA test was applied. Tukey HSD post-hoc test was done to indicate which groups were significantly different from which others. This statistical analysis was done with statpages.info software $\mathrm{P}$ value $<0.05-$ considered as Statistically Significant.

\section{Results}

This cross sectional study was consisted of 250 children with delayed speech. They were similar with corresponding control population in respect to age where each group was consisted of 30 normal children. BAEP parameters, latencies of wave I, wave III, wave $\mathrm{V}$, and I-V inter wave latency were recorded and compared between control groups and each group of case population. The result of the study was represented below in the form of tables.

\section{Group $1(<1$ yr)}

\section{Left Ear}

Out of 60 infants with delayed speech, at $70 \mathrm{~dB}$ intensity, all the waves were present in 33 infants (55\%) and absent in 27(45\%) infants.

\section{Mean Wave Latencies of Cases and Controls at 70 dB}

Table 1a - Mean Wave latencies of Cases and Controls of left ear with $p$-value

\begin{tabular}{|c|c|c|c|}
\hline $\begin{array}{l}\text { BAEP Parameters } \\
\text { Latency }(\mathrm{mS})\end{array}$ & $\begin{array}{c}\text { CASE } \\
\text { Mean(SD) } \\
(\mathbf{n}=33)\end{array}$ & $\begin{array}{c}\text { CONTROL } \\
\text { Mean(SD) } \\
(\mathbf{n}=\mathbf{3 0})\end{array}$ & $\begin{array}{c}\mathbf{P} \\
\text { Value }\end{array}$ \\
\hline Wave I & $1.96(.37)$ & $1.86(.03)$ & .15 \\
\hline Wave III & $4.27(.64)$ & $4.49(.17)$ & .07 \\
\hline Wave V & $6.52(.73)$ & $6.44(.2)$ & .56 \\
\hline Wave I-V inter peak latency & $4.6(.85)$ & $4.58(.21)$ & .9 \\
\hline
\end{tabular}




\section{Right Ear}

Out of 60 infants with delayed speech, at $70 \mathrm{~dB}$ intensity, all the waves were present in 43 infants (71.67\%) and absent in 17(28.33\%) infants.

Mean Wave Latencies of Cases and Controls at $70 \mathrm{~dB}$

Table 1b - Mean Wave latencies of Cases and Controls of right ear with p-value

\begin{tabular}{|l|c|c|c|}
\hline $\begin{array}{l}\text { BAEP } \\
\text { Parameters } \\
\text { Latency(mS) }\end{array}$ & $\begin{array}{c}\text { CASE } \\
\text { Mean(SD) } \\
(\mathbf{n = 4 3 )}\end{array}$ & $\begin{array}{c}\text { CONTROL } \\
\text { Mean(SD) } \\
(\mathbf{n = 3 0})\end{array}$ & P Value \\
\hline Wave I & $1.92(.19)$ & $1.85(.03)$ & $\mathbf{. 0 4 9 7 *}$ \\
\hline Wave III & $4.22(.66)$ & $4.46(.11)$ & .053 \\
\hline Wave V & $6.44(.84)$ & $6.42(.16)$ & .9 \\
\hline $\begin{array}{l}\text { Wave I-V inter } \\
\text { peak latency }\end{array}$ & $4.52(.91)$ & $4.56(.17)$ & .81 \\
\hline \\
$\begin{array}{l}\text { P value <.05 was considered as statistically significant } \\
\text { mS-milisecond * statistically significant }\end{array}$
\end{tabular}

According to Table: 1a, there were no statistically significant prolongation of Waves and I-V inter peak latency at $70 \mathrm{~dB}$ compared to control whereas according to Table: $1 \mathrm{~b}$, wave I was statistically significantly prolonged in right ear of the cases.

\section{Group 2 (1-3yr)}

\section{Left Ear}

Out of 80 children with delayed speech, at $70 \mathrm{~dB}$ intensity, all the waves were present in 33 babies $(41.25 \%)$ and absent in $47(58.75 \%)$ babies.

\section{Mean Wave Latencies of Cases and Controls at $70 \mathrm{~dB}$}

Table 2a - Mean Wave latencies of Cases and Controls of left ear with p-value

\begin{tabular}{|c|c|c|c|}
\hline $\begin{array}{l}\text { BAEP } \\
\text { Parameters } \\
\text { Latency }(\mathrm{mS})\end{array}$ & $\begin{array}{c}\text { CASE } \\
\operatorname{Mean}(\mathbf{S D}) \\
(\mathbf{n}=\mathbf{3 3})\end{array}$ & $\begin{array}{c}\text { CONTROL } \\
\text { Mean(SD) } \\
(\mathbf{n}=\mathbf{3 0})\end{array}$ & P Value \\
\hline Wave I & $1.98(.36)$ & $1.82(.08)$ & $.02 *$ \\
\hline Wave III & $4.43(.84)$ & $4.25(.26)$ & .7 \\
\hline Wave V & $6.92(.72)$ & $6.16(.21)$ & $.0001 *$ \\
\hline $\begin{array}{l}\text { Wave I-V inter } \\
\text { peak latency }\end{array}$ & 4.94(.78) & $4.34(.2)$ & $.0001 *$ \\
\hline
\end{tabular}

\section{Right Ear}

Out of 80 children with delayed speech, at $70 \mathrm{~dB}$ intensity, all the waves were present in 30 babies (37.5\%) and absent in 50(62.5\%) babies.

Mean Wave Latencies of Cases and Controls at $70 \mathrm{~dB}$
Table 2b - Mean Wave latencies of Cases and Controls of right ear with $p$-value

\begin{tabular}{|l|c|c|c|}
\hline $\begin{array}{l}\text { BAEP } \\
\text { Parameters } \\
\text { Latency(mS) }\end{array}$ & $\begin{array}{c}\text { CASE } \\
\text { Mean(SD) } \\
(\mathbf{n = 3 0})\end{array}$ & $\begin{array}{c}\text { CONTROL } \\
\text { Mean(SD) } \\
(\mathbf{n = 3 0})\end{array}$ & P Value \\
\hline Wave I & $2.04(.31)$ & $1.82(.08)$ & $\mathbf{. 0 0 0 4} *$ \\
\hline Wave III & $4.44(.68)$ & $4.28(.25)$ & .23 \\
\hline Wave V & $6.78(.75)$ & $6.2(.21)$ & $\mathbf{. 0 0 0 1} *$ \\
\hline $\begin{array}{l}\text { Wave I-V inter } \\
\text { peak latency }\end{array}$ & $4.74(.63)$ & $4.35(.2)$ & $\mathbf{. 0 0 2}^{*}$ \\
\hline $\begin{array}{l}\text { P value <.05 was considered as statistically significant } \\
\text { mS-milisecond * statistically significant }\end{array}$
\end{tabular}

According to Table: $2 \mathrm{a} \& 2 \mathrm{~b}$, There were statistically significant prolongation of Waves I,V and I-V inter peak latency at $70 \mathrm{~dB}$ compared to controlin both the ears.

\section{Group 3 (3-6yrs) \\ Left Ear}

Out of 70 children with delayed speech, at $70 \mathrm{~dB}$ intensity, all the waves were present in 29 babies $(41.43 \%)$ and absent in 41(58.57\%) babies.

Mean Wave Latencies of Cases and Controls at $70 \mathrm{~dB}$

Table 3a - Mean Wave latencies of Cases and Controls of left ear with p-value

\begin{tabular}{|l|c|c|c|}
\hline $\begin{array}{l}\text { BAEP Parameters } \\
\text { Latency(mS) }\end{array}$ & $\begin{array}{c}\text { CASE } \\
\text { Mean(SD) } \\
(\mathbf{n}=\mathbf{2 9})\end{array}$ & $\begin{array}{c}\text { CONTROL } \\
\text { Mean(SD) } \\
(\mathbf{n}=\mathbf{3 0})\end{array}$ & P Value \\
\hline Wave I & $1.92(.48)$ & $1.72(.02)$ & $\mathbf{. 0 3 *}$ \\
\hline Wave III & $4.17(.19)$ & $3.94(.04)$ & $\mathbf{. 0 0 0 1} *$ \\
\hline Wave V & $6.56(.5)$ & $5.77(.09)$ & $\mathbf{. 0 0 0 1} *$ \\
\hline $\begin{array}{l}\text { Wave I-V inter peak } \\
\text { latency }\end{array}$ & $4.82(1)$ & $4.05(.08)$ & $\mathbf{. 0 0 0 1 *}$ \\
\hline \\
$\begin{array}{l}\text { P value <.05 was considered as statistically significant } \\
\text { mS-milisecond * statistically significant }\end{array}$
\end{tabular}

\section{Right Ear}

Out of 70 children with delayed speech, at $70 \mathrm{~dB}$ intensity, all the waves were present in 37 babies $(52.86 \%)$ and absent in 33(47.14\%) babies.

\section{Mean Wave Latencies of Cases and Controls at $70 \mathrm{~dB}$}

Table 3b - Mean Wave latencies of Cases and Controls of right ear with $\mathrm{p}$-value

\begin{tabular}{|l|c|c|c|}
\hline $\begin{array}{l}\text { BAEP } \\
\text { Parameters } \\
\text { Latency(mS) }\end{array}$ & $\begin{array}{c}\text { CASE } \\
\text { Mean(SD) } \\
(\mathbf{n}=\mathbf{3 7})\end{array}$ & $\begin{array}{c}\text { CONTROL } \\
\text { Mean(SD) } \\
(\mathbf{n = 3 0})\end{array}$ & P Value \\
\hline Wave I & $1.83(.33)$ & $1.74(.02)$ & .14 \\
\hline Wave III & $4.17(.5)$ & $3.95(.04)$ & $\mathbf{. 0 2} *$ \\
\hline Wave V & $6.4(.56)$ & $5.79(.09)$ & $\mathbf{. 0 0 0 1} *$ \\
\hline $\begin{array}{l}\text { Wave I-V inter } \\
\text { peak latency }\end{array}$ & $4.58(.74)$ & $4.06(.08)$ & $\mathbf{. 0 0 0 3} *$ \\
\hline $\begin{array}{l}\text { P value <.05 was considered as statistically significant } \\
\text { mS-milisecond * statistically significant }\end{array}$
\end{tabular}

According to Table: 3a, There were statistically significant prolongation of all the Waves and I-V 
inter peak latency at $70 \mathrm{~dB}$ compared to control whereas according to Table: $3 \mathrm{~b}$, all waves except wave I were statistically significantly prolonged in right ear of the cases .

\section{Group 4 (6-12yrs)}

\section{Left Ear}

Out of 40 children with delayed speech, at $70 \mathrm{~dB}$ intensity, all the waves were present in 22 babies (55\%) and absent in $18(45 \%)$ babies.

\section{Mean Wave Latencies of Cases and Controls at $70 \mathrm{~dB}$}

Table 4a - Mean Wave latencies of Cases and Controls of left ear with p-value

\begin{tabular}{|l|c|c|c|}
\hline $\begin{array}{l}\text { BAEP } \\
\text { Parameters } \\
\text { Latency(mS) }\end{array}$ & $\begin{array}{c}\text { CASE } \\
\text { Mean(SD) } \\
(\mathbf{n = 2 2})\end{array}$ & $\begin{array}{c}\text { CONTROL } \\
\text { Mean(SD) } \\
(\mathbf{n = 3 0})\end{array}$ & P Value \\
\hline Wave I & $1.93(.48)$ & $1.68(.02)$ & $\mathbf{. 0 0 6}^{*}$ \\
\hline Wave III & $4.03(.54)$ & $3.91(.09)$ & .24 \\
\hline Wave V & $6.54(.67)$ & $5.63(.02)$ & $\mathbf{. 0 0 0 1} *$ \\
\hline $\begin{array}{l}\text { Wave I-V inter } \\
\text { peak latency }\end{array}$ & $4.62(1.02)$ & $3.96(.01)$ & $\mathbf{. 0 0 0 1} *$ \\
\hline $\begin{array}{l}\text { P value <.05 was considered as statistically significant } \\
\text { mS-milisecond * statistically significant }\end{array}$
\end{tabular}

\section{Right Ear}

Out of 40 children with delayed speech, at $70 \mathrm{~dB}$ intensity, all the waves were present in 10 babies $(25 \%)$ and absent in 30(75\%) babies.

\section{Mean Wave Latencies of Cases and Controls at $70 \mathrm{~dB}$}

Table 4b - Mean Wave latencies of Cases and Controls of right ear with $\mathrm{p}$-value

\begin{tabular}{|l|c|c|c|}
\hline $\begin{array}{l}\text { BAEP } \\
\text { Parameters } \\
\text { Latency }(\mathbf{m S})\end{array}$ & $\begin{array}{c}\text { CASE } \\
\text { Mean(SD) } \\
(\mathbf{n = 1 0})\end{array}$ & $\begin{array}{c}\text { CONTROL } \\
\text { Mean(SD) } \\
(\mathbf{n = 3 0})\end{array}$ & P Value \\
\hline Wave I & $1.93(.07)$ & $1.69(.03)$ & $\mathbf{. 0 0 0 1 *}$ \\
\hline Wave III & $3.88(.24)$ & $3.93(.09)$ & .34 \\
\hline Wave V & $5.41(.76)$ & $5.65(.02)$ & .08 \\
\hline $\begin{array}{l}\text { Wave I-V inter } \\
\text { peak latency }\end{array}$ & $3.48(.72)$ & $3.96(.02)$ & $\mathbf{. 0 0 0 1 *}$ \\
\hline $\begin{array}{l}\text { P value <.05 was considered as statistically significant } \\
\text { mS-milisecond * statistically significant }\end{array}$
\end{tabular}

According to Table: 4a, there were statistically significant prolongation of I,V Waves and I-V inter peak latency at $70 \mathrm{~dB}$ compared to control. According to Table: 4b, wave I was statistically significantly prolonged but there was no significant prolongation of wave $\mathrm{V}$ latency. So,I-V inter peak latency were statistically significantly reduced in right ear of the cases, which is normal.
Table 9a. ANOVA test for intragroup comparison of all the BAEP Parameters

\begin{tabular}{|lccccc|}
\hline $\begin{array}{l}\text { BAEP } \\
\text { parameters }\end{array}$ & \multicolumn{5}{c|}{ GROUPS } \\
& GEAN(SD) & \\
& 1 & Group & Group & Group & P \\
& $1.96(.37)$ & $1.98(.36)$ & $1.92(.48)$ & $1.93(.48)$ & 0.94 \\
\hline Lt I & $1.92(.19)$ & $2.04(.31)$ & $1.83(.33)$ & $1.93(.07)$ & $\mathbf{0 . 0 2} *$ \\
\hline Rt I & $4.27(.64)$ & $4.43(.84)$ & $4.17(.19)$ & $4.03(.54)$ & 0.11 \\
\hline Lt III & $4.22(.66)$ & $4.44(.68)$ & $4.17(.5)$ & $3.88(.24)$ & 0.06 \\
\hline Rt III & $6.52(.73)$ & $6.92(.72)$ & $6.56(.5)$ & $6.54(.67)$ & 0.06 \\
\hline Lt V & $6.44(.84)$ & $6.78(.75)$ & $6.4(.56)$ & $5.41(.76)$ & $\mathbf{0 . 0 0 *}$ \\
\hline Rt V & $4.6(.85)$ & $4.94(.78)$ & $4.82(1)$ & $4.62(1.02)$ & 0.4 \\
\hline Lt I-V & $4.52(.91)$ & $4.74(.63)$ & $4.58(.74)$ & $3.48(.72)$ & $\mathbf{0 . 0 0 3 *}$ \\
\hline Rt I-V & & & &
\end{tabular}

Table 9b Post-Hoc Test of intragroup right wave I

\begin{tabular}{|l|c|c|c|}
\hline Group & Vs & Group & P value \\
\hline Group1 & Vs & Group2 & 0.24 \\
\hline Group1 & Vs & Group3 & 0.44 \\
\hline Group1 & Vs & Group4 & 0.99 \\
\hline Group2 & Vs & Group3 & $\mathbf{0 . 0 1} *$ \\
\hline Group2 & Vs & Group4 & 0.67 \\
\hline Group3 & Vs & Group4 & 0.72 \\
\hline
\end{tabular}

Table 9c Post-Hoc Test of intragroup right wave $\mathrm{V}$

\begin{tabular}{|l|c|c|c|}
\hline Group & Vs & Group & P value \\
\hline Group1 & Vs & Group2 & 0.21 \\
\hline Group1 & Vs & Group3 & 0.99 \\
\hline Group1 & Vs & Group4 & $\mathbf{0 . 0 0 0 6} *$ \\
\hline Group2 & Vs & Group3 & 0.16 \\
\hline Group2 & Vs & Group4 & $\mathbf{0 . 0 0 *}$ \\
\hline Group3 & Vs & Group4 & $\mathbf{. 0 0 1}^{*}$ \\
\hline
\end{tabular}

Table 9c. Post-Hoc Test of intragroup right I-V inter wave latency

\begin{tabular}{|l|c|c|c|}
\hline Group & Vs & Group & P value \\
\hline Group1 & Vs & Group2 & 0.64 \\
\hline Group1 & Vs & Group3 & 0.99 \\
\hline Group1 & Vs & Group4 & $\mathbf{0 . 0 0 1} *$ \\
\hline Group2 & Vs & Group3 & 0.84 \\
\hline Group2 & Vs & Group4 & $\mathbf{0 . 0 0 0 1 *}$ \\
\hline Group3 & Vs & Group4 & $\mathbf{. 0 0 0 8}^{*}$ \\
\hline
\end{tabular}

These tables showed that right sided wave I latency was statistically significantly prolonged in group 2 than group 3. Right sided wave $\mathrm{V}$ latencies and I-V inter wave latencies were statistically significantly prolonged in group 1,2,3 in respect to Group 4.

\section{Discussion}

BAEP parameters of 250 children with delayed speech, divided into 4 groups according to age, were measured and compared with 120 normal children of similar age. Intragroup comparison was also done. The BERA study was performed to assess functional integrity of the auditory pathway among children with impaired speech. Initially 
comparison between cases and controls were done. Group 1, consisted of <1yr infants, showed statistically significant prolongation of wave I in right ear. This was suggestive peripheral auditory pathway involvement in right side. Group 2, consisted of 1-3 yrs. of children, showed statistically significant prolongation of Waves I, V and I-V inter peak latency in both the ears. This was suggestive of peripheral \& central auditory pathway involvement in both the sides. Group3, consisted of 3-6 yrs. children, showed, statistically significant prolongation of all the Waves and I-V inter peak latency in left side and significant delay of all waves except wave I in right side. This was suggestive of peripheral and central auditory pathway involvement in left side and central auditory pathway involvement in right side. Group 4, consisted of children of 6-12 yrs., showed, statistically significant prolongation of I, V Waves and I-V inter peak latency in left side andstatistically significant delay of wave I in right ear. This was suggestive of peripheral and central auditory pathway involvement in left side and peripheral auditory pathway involvement in right side. In next step, intragroup comparison was done. It showed, right sided wave I latency was statistically significantly prolonged in group 2 than group 3. It means, right sided peripheral pathway was more affected in toddlers in comparison with preschool children. Another finding was right sided statistically significantly prolongation of wave $\mathrm{V}$ latencies and $\mathrm{I}-\mathrm{V}$ inter wave latencies in group 1,2,3 in respect to Group 4.So, the interpretation is, right sided central pathway was more affected in infants, toddlers and preschool children in comparison with school children.

In each group, children with absence of all the waves were also present. This absence is either due to non-uniform delay of neuronal activity in auditory pathway or due to desynchronization of electrical signals and the summation possibly cannot produce a recognizable wave. Same patho physiological process can cause either delay or absence of a BAEP peaks. Not only central pathway dysfunction, but also peripheral auditory pathway involvement alone is sufficient to cause complete absence of BAEP.

Many workers had presented the relation between delayed speech and hearing impairment.

Psarommatis IM et al showed that among 654 speech-language delayed children, 55 children, $(8.4 \%)$ were suffering from sensorineural hearing impairment, while in 32 children $(4.9 \%)$ were affected with conductive hearing loss. ${ }^{[1]}$

Al-Kandari JM worked with children of 1 to 12 years with pathological speech development.

Among them, 63\% had some level (mildprofound) of hearing impairment which actually caused the delay in speech development; ${ }^{[4]}$

Tomblin JB et al said that Hearing loss (HL) in children can be deleterious to their speech and language development. Early provision of hearing aids (HAs) can improve degree of hearing with better speech and language development in children. ${ }^{[5]}$

Husain A showed that among, 173 patients with delayed speech, BERA could identify $64.6 \%$ of patients with hearing deficit. ${ }^{[6]}$

Psillas $G$ assessed hearing in 76 children aged 1-5 $\mathrm{y}$ with speech delay. ABER was abnormal in $31.6 \%$ of children ${ }^{[7]}$

There are contradictory findings too

King $C$ showed there was no prolongation of wave latencies in click evoked BAEPs in a group of children with language based learning impairments ${ }^{[8]}$. Filippini and Schochat also found no changesin a click evoked BAEP for individuals with an auditory processing disorder when compared to a control group ${ }^{[9]}$.

Hussain $\mathrm{A}^{[6]}$ showed out of 173 children aged between 1.4 years to 10 years, 6 children was suffering from conductive hearing loss, and 27 children were suffering from peripheral hearing loss. 49 children were suffering from sensorineural hearing loss and among them 55\% showed cochlear involvement and $4 \%$ showed retro cochlear involvement.

In this study, there were two types of BAEP interpretation based on wave latencies. 
Prolongation of wave III, V or I-V inter wave latencies suggest presence of pathology in central pathway (retro cochlear involvement). Another finding was delayed wave I. It means presence of pathology anywhere in external ear or middle ear, or cochlea or distal part of auditory nerve ${ }^{[2]}$. External ear causes were already excluded by preliminary examination and to confirm cochlear involvement otoacoustic emissions (OAEs) and cochlear microphonic responses (CMs) have to be done.

There were certain limitations of this study. It was not possible to collect detail history of each patient regarding antenatal, natal and postnatal factors like $\mathrm{H} / \mathrm{O}$ hyperbilirubinaemia, preterm, low birth weight, hypoxia, birth or postnatal injury, drug history. So, the possible cause of auditory pathway involvement remained unclear. BERA is very good for screening purpose but to confirm type of hearing loss or exact location of pathology only BERA test is not sufficient. This should be followed by ear microscopy ${ }^{[10]}$, high frequency tympanometry for children $<9 \mathrm{~m}$, tympanometry with $1000 \mathrm{~Hz}$ for older children $^{[11,12]}$, OAEs etc. Based on the results of all these tests Cochlear implant or Hearing aid can be prescribed which is beneficial for linguistic development.

\section{Conclusion}

Delayed speech in children is a multifactorial entity. Among different causes, hearing impairment plays a major part. This study was done to find out whether there were significant changes in auditory pathway which leads to language impairment among a group of children of different age group. For this BERA test was done as screening tool, which not only showed children with auditory causes of delayed speech, but also grossly provided an idea about the location of pathology. Where, with comparison with normal control population, study group showed both retrocochlear and cochlear or middle ear involvement; In intragroup comparison retro cochlear involvement was more in infant, toddlers and preschool children than school children.

This diagnosis should be done at earliest. As earlier the diagnosis is confirmed, it helps to initiate the treatment earlier in the form cochlear implant or hearing aid and the outcome gets better. With the improved hearing, speech delay would be corrected automatically or it would be getting better with the help of speech therapy.

\section{References}

1. Psarommatis IM, Goritsa E, Douniadakis D, Tsakanikos M, Kontrogianni AD, Apostolopoulos N. Hearing loss in speechlanguage delayed children. Int J Pediatr Otorhinolaryngol. $2001 \quad$ May 11;58(3):205-10.

2. Aminoff MJ. Electrodiagnosis in clinical neurology. $4^{\text {th }}$ edition, Part II, San Francisco: Churchill Livingstone; 1999:451-491.

3. Ray R, Ghosh N. A demographic study of hearing loss among children below 5 yrs in a rural tertiary care hospital. IOSR Journal of Dental and Medical Sciences (IOSRJDMS).2018 August;17(8): PP 39-42. DOI: 10.9790/0853-1708113942.

4. Al-Kandari JM, Alshuaib WB, Joe M . BERA in children with hearing loss and delayed speech. Electromyogr Clin Neurophysiol. 2006 Jan-Feb;46(1):43-9.

5. Tomblin JB,Bruce J,Jacob J. Oleson, Ambrose SE, Walker E, Moeller MP. The Influence of Hearing Aids on the Speech and Language Development of Children With Hearing Loss. JAMA Otolaryngol Head Neck Surg. 2014 May 1; 140(5): 403-409. doi: 10.1001/jamaoto.2014.267.

6. Husain A.A Auditory Brain Stem Evoked Responses (ABRS) in Children with Delayed Speech (DS) a Diagnostic Problem. IJO \& HNS. 1994;46(4): P19196.

7. Psillas G, Psifidis A, Antoniadou-Hitoglou M, Kouloulas A. Hearing assessment in 
pre-school children with speech delay. Auris Nasus Larynx. 2006; 33:259-63.

8. King C, Warrier CM, Hayes E, Kraus N. Deficits in auditory brainstem pathway encoding of speech sounds in children with learning problems. Neurosci Lett. 2002; 319:111-15.

9. Filippini R, Schochat E. Brainstem evoked auditory potentials with speech stimulus in the auditory processing disorder.Braz $\mathrm{J}$ Otorhinolaryngol. 2009; 75:449-55.

10. Rogers DJ, Boseley ME, Adams MT, Makowski RL, Hohman MH. Prospective comparison of handheld pneumatic otoscopy, binocular microscopy, and tympanometry in identifying middleear effusions in children. Int $J$ Pediatr Otorhinolaryngol. 2010Oct;74(10):1140-3. DOI: 10.1016/j.ijporl.2010.06.015.

11. Hoffmann A, Deuster D, Rosslau K, Knief A, Am Zehnhoff-Dinnesen A, Schmidt CM. Feasibility of $1000 \mathrm{~Hz}$ tympanometry in infants: tympanometric trace classification and choice of probetone in relation to age. Int $\mathrm{J}$ Pediatr Otorhinolaryngol. 2013 Jul;77(7):1198203. DOI: 10.1016/j.ijporl.2013.05.001

12. Mazlan R, Kei J, Hickson L, Gavranich J, Linning R. Test-retestreproducibility of the $1000 \mathrm{~Hz}$ tympanometry test in newborn and six-week-old healthy infants. Int $\mathrm{J}$ Audiol. 2010Nov;49(11):815-22. DOI: 10.3109/14992027.2010.493182. 